most oscillograms and on records taken by a sufficiently "quick" and sensitive string are due to slight muscular contraction or tone. Of course a treinulous tracing can be due to other causes, such as a shaky building or a spitting arc or $t$ ) alternating current in the vicinity of the instrument. Bat over and above these causes there is a true muscular tremor which can be exaggerated at will by voluntary contraction, and which in animals can be abolished by chloroform.

But in another and more important respect oscillographs are in general preferable to string records for clinical purposes. The larger and quicker indications of the former are better adapted to measurement than are the smaller and slower indications of the latter; the lengths of the auriculoventricular interval and of the ventricular systole are easier to measure ; and the variations of amplitude of the spike on the two sides of the body and in the phases of respiration are far better compared by the comparatively quick than by a comparatively slow recorder. And as supplied by the instrument maker, the deflection time of an oscillograph mirror does not much exceed 0.005 sec. with an amplitude of $2 \mathrm{c.m}$. per millivolt, while that of an average string is at least $0.020 \mathrm{sec}$. for a deflection of $1 \mathrm{c.m}$. The greater height of the spike, as given by the oscillograph, even if due to "overshoot," could be of no disadvantage, since it would be a proportional augmentation of all deflections; but as a matter of fact the greater height of the spike in an ordinary oscillograph record as compared with an ordinary string record is a sign that the quicker instrument has followed the development of electromotive force during this phase more perfectly than was the case with the slower instrument. The smaller and slower indications of a string adjusted to give $1 \mathrm{c.m}$. deflection by one millivolt can of course be magnified for purposes of measurement, but to do this costs time and at best gives less satisfactory results than does the direct measurement of the corresponding oscillogram.

To return to the question-" What is the best instrument for clinical purposes ?" or otherwise put "Which instrument is best to buy? - the Cambridge model or the Bock-Thoma?" I can only say that I like both instruments in a laboratory. I like the Cambridge model for cases where I want to get an electrocardiogram of most conventional size and form. I like the Bock-Thoma for routine use because of its quickness, and because it is a more sensitive indicator of the varying amplitudes of the ventricular spike, and I am sure that in a laboratory or in the special electrocardiographic department of a hospital, if there is a use for either of these instruments, there is a use for both. But there is at present a tendency to lay too much stress upon the form of the electrocardiogram and upon the relative magnitudes of its various peaks and depressions. Variations of tension of the string during an observation are of frequent occurrence, and the precaution of recording the standard deflection after as well as before taking a record should never be omitted if its form is to be studied. Variations of form, such as the presence or absence of $Q$, the augmentation of S giving the so-called "nervous notch" of some clinicians, the relative augmentation or diminution of $T$, are features that may possibly be of pathological significance, but that may also be of purely instrumental origin if the tension of the string has not been tested after as well as before every observation. A considerable altera. tion of tension is indeed possible before gross and obvious modification of form appears ; and, after all, modification of form is of much less importance than the comparison of records from different leads and the observation of disordered rhythm.

Physiological Laboratory, University of London, S. Kensington.

Medical Temperance Committee.-The final meeting of the committee which was responsible for the organisation of the lectures on alcohol which were delivered during the recent Brighton conference of the British Medical Association was held on July 31st, and much satisfaction was expressed at the success which crowned its labours. The lectures delivered by eminent members of the profession were, the committee states, of a high order and well attended, and it was felt that a considerable number of persons were reached who were not usually touched by the ordinary methods of the temperance propaganda. The committee decided to place on record its gratitude to the medical men who had rendered such splendid service gratis, and to hand over a balance of abrout $£ 6$ to the United Temperance Couneil.

\section{THE ALBUMIN REACTION IN SPUTUM: ITS SIGNIFICANCE AND CAUSATION.}

BY PERCY B. RIDGE, M.B. R.U.I.,

PATHOLOGIST TO THE ROYAL CHHST HOSPITAI, CITY-ROAD, E.C., ANE ASSISTANT PATHOLOGIST TO KING"S COLLEGE HOSPITAL;

AND

H. A. TREADGOLD, M.D. LOND., ASSISTANT SUPERTNTENDENT OF THE CLINICAL LABORATORIES, IBROMP'TON CHEST HOSPI'AAL.

(From the Pathological Laboratory, Royal Chest IIospital, City-road, E.C.)

THE subjects of these inquiries have been, firstly, therelation between active pulmonary tuberculosis and the appearance of albumin in the sputum; and secondly, the establishment, if possible, of the pathological condition associated with albuminous sputa. The presence of albumin in the sputum was described originally by Biermer ' in 1855. In his investigation he mixed the sputum with water, filtered, and precipitated the albumin by heat after acidification. He claimed that the amount of albumin present was proportional to the cytological content, and was present in all sputa, in. contradistinction to Renk, who at a later date claimed it absent in chronic bronchitis. Wanner in 1903 investigated the question more fully. His technique consisted in diluting the sputum with an equal volume of 3 per cent. acetic acid in order to precipitate all mucin, neutralising the excess of acid, adding sodium chloride to provide electrolytes for the coagulation of the albumin by heat, and finally weighing the precipitate after washing in hot water, alcohol, and ether. His conclusions were that albumin was present in practically all sputa. More recently Roger ${ }^{2}$ and Levy Valensi ${ }^{3}$ investigated the question of its presence in pulmonary tuberculosis under the title of the albumin reaction. Their technique was similar to that of Wanner, except that they mixed the sputum with an equal volume of water, afterwards precipitating the mucus with dilute acetic acid.

In $1911,{ }^{4}$ replying to objections raised by Goggia ${ }^{5}$ that putrefaction decomposes the proteins in sputum, especially mucin, and sets more albumin at liberty, Roger and Levy Valensi maintained that they always advocated the use of fresh specimens; and in answer to Remlinger ${ }^{6}$ they completely deny his assertion that all sputa contain traces of albumin. Whilst agreeing that albumin is present in pneumonias, passive congestion, œdema, and all cases of pulmonary tuberculosis, they assert that it is never present in acute and chronic bronchitis, and claim that if albumin is absent from the sputum in suspected cases of pulmonary tuberculosis after two examinations it is certain. that the case is not tuberculous. They then proceed to analyse the few cases of pulmonary tuberculosis in the literature, which contained no albumin in the sputum. In cases of the second and third degrees there were 4 out of 897 . In one case no sodium chloride was added when the coagulation test was employed. In two others no tubercle bacilli were ever found, and in the fourth one or two doubtfal bacilli were seen once after many examinations. In cases of the first degree 13 were negative out of 288 , or $4 \cdot 5$ per cent., and they criticise the technique employed in several of the cases and quote figures to show that in early pulmonary tuberculosis, before physical signs have appeared, at least 50 per cent. to. 70 per cent. of cases have albumin. They quote Dieudonnê on the increased amount of albumin present in exacerbations produced by tuberculin and other causes. Of 19 cases considered as healed and examined by him 8 showed a few tubercle bacilli by antiformin only, and in these the albumin reaction was positive. In 7 tubercle bacilli had recently disappeared, and the albumin reaction was positive in all. In 4 others considered as cured for two years the albumin reaction was negative. Dieudonné claims that the test is of the utmost value in distinguishing between bronchitic and

1 Biermer: Die Lehre vom Auswurf, Würzburg, 1855.
2 Roger: Société Médicale des Hôpitaux, October, 1909. 3 Roger and Levy Valensi : Ibid., 1909, vol, xxviii., Sér. 32, p. 3.

4 Roger and Levy Valensi : La Presse Médicale. 1911, vol. xix., p. 409.

C Goggia: Gazzetta degli Ospedali, July, 1910.

? Dieudonné: Revue Médicale de la Suisse Romande, 1910, vol. xxx 
tuberculous sputa in these cases; and this opinion is upheld by Geeraerd, ${ }^{8}$ who agrees that the disappearance of albumin in cases of pulmonary tuberculosis is pathognomonic of complete cure. Lesieur and Privey ${ }^{9}$ dilute the sputum with four times its volume of normal saline, and test for the albumin, after acidification with 3 per cent. acetic acid, with strong nitric acid. Their results are as follows :-

Tubercle bacilli present $\quad \ldots \quad \ldots \quad \ldots \quad \ldots \quad$ Albumin $+\quad 100$ per cent.

$\left.\begin{array}{ccccccc}\text { Clinically tuberculosis, but no tubercle } \\ \text { bacilli found } & \ldots & \ldots & \ldots & \ldots & \ldots & \ldots\end{array}\right\} \quad " \quad+\quad 82 \quad "$

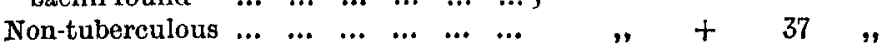

Nathan Raw, ${ }^{10}$ adopting the same technique in 110 cases, obtains lower percentages, but considers the test requires further investigation.

Spiers Fullerton ${ }^{11}$ found that albumin was absent or inconsiderable in 50 per cent. of phthisical and in 86 per cent. of non-phthisical cases; it was considerable in 50 per cent. tuberculous and 14 per cent. non-tuberculous, Albumin was present in considerable amount in acute bronchitis, pneumonia, and bronchiectasis. He concludes that in consequence the test is only of limited valve, but that if much albumin is present in a case of bronchial catarrh not due to these causes, tuberculosis should be suspected. Fishberg and Felberbaum ${ }^{12}$ describe cases of undoubted phthisis where albumin was absent, and point out that the amount bears no relation to the stage of the disease. They conclude by saying that the test will often shed some light on a case which may otherwise prove puzzling.

More recently Kauffmann ${ }^{13}$ agrees that albumin is present in active pulmonary tuberculosis, pneumonias, congestion, and cedema of the lung and absent in chronic bronchitis, and considers that the presence of albumin in doubtful cases of pulmonary tuberculosis is strong evidence of active disease, whereas in healed cases albumin is absent. $\mathrm{He}$ finds that in lobar pneumonia albumin disappears after the crisis, and if remaining, suggests a new pneumonic focus or an empyema.

In considering this literature, which, all told, comprises under 2000 cases, it is evident that there is a general consensus of opinion that the albumin reartion is fairly constantly present in active pulmonary tuberculosis. But there seems to be considerable confusion as to its significance and its occurrence in other diseases. The results of the following investigation confirm the former claim and suggest a reasonable explanation of the latter.

The results are based on an analysis of 2164 specimens undertaken in two series. In the first, 2000 specimens were examined, the method being that of Lesieur and Privey. The findings, indicated in Table I., show that the vast majority

TABLE I.-Analysis of 2000 cases.

Tubercle bacilli present in 615 specimens.

$$
\text { , " not found in } 1385
$$

Tuberculous specimens $\quad \ldots\left\{\begin{array}{l}\text { Albumin }+ \text { in } 96.4 \text { per cent. } \\ \text { (Trace in } 74.4 \text { per cent.) } \\ \text { Albumin }- \text { in } 3.6 \text { per cent. }\end{array}\right.$
Non-tuberculous specimens $\left\{\begin{array}{l}\text { Albumin }+ \text { in } 32 \text { per cent. } \\ \text { (Trace only in } 60 \text { per cent.) } \\ \text { Albumin - in } 68 \text { per cent. }\end{array}\right.$

of tuberculous specimens ( 96.4 per cent.) contain albumin, and in approximately two-thirds of all other sputa which do not contain tubercle bacilli albumin is absent. This figure should in reality be higher owing to the fact that many of the cases in which tubercle bacilli were not found were diagnosed as undoubted clinical tubercle.

In the second series 164 specimens were examined. The sputum extract was obtained as in the first series, and the complete technique employed is as follows:-

The sputum, which should not be more than 12 hours old, is poured on to a Petri dish and examined on a dark surface. The purulent portions are selected and all clear mucin discarded, as the albumin is portions are selected and all clear mucin discarded, as the albumin is only present in the former. To one volume of sputum four volumes of saline $(0.85$ per cent.) are added, and the whole shaken up in a small Erlenmeyer flask filled with a rubber cork until homogeneous. This 3 per cent. acetic acid are now added until the contents of the flask are

8 Geeraerd: Tuberculosis, 1910, vol. ix., p. 372

9 Lesieur and Privey : Paris Médical, 1911, vol. xiv.,p. 29

It Spiers Fullerton: Glasgow Medico-Chirurgical Society, Jan. 19th,

1912.

2 Fishberg and Felberbaum: Medical Record, 1911, vol. ii., p. 870. p. 269 . just acid to litmus paper. The emulsion is filtered through moist filter paper and the filtrate divided into three portions-(1) control, (2) for bolling, and (3) for nitric acid test. The nucleo-albumin, albumoses, and mucin are precipitated by the saline and acetic acid, only albumin and globulin appearing in the filtrate.

In testing for albumin the boiling test is more sensitive than nitric acid, for occasionally specimens give no ring with nitric acid, whereas a distinct cloud may appear on boiling. In this series the percentage of albumin-free specimens is therefore less than in the former, but a too strict comparison cannot be made, as many of the specimens in the first series were drawn from the chronic bronchitic class of out-patients, such specimens being free from albumin, whereas the vast majority of cases in the second series were supplied by in-patients and in the latter a lower percentage of albuminfree specimens would be expected, as chronic bronchitics are rarely admitted as in-patients. In this series the cytological content of the specimens was also investigated, the method of examination being that recommended by Besançon and de Jong. ${ }^{14}$

A thin film of sputum is spread with a platinum loop on a clean slide. It is fixed by dipping into 1 per cent. chromic acid for 2 seconds, washed in tap water for an equal time, and stained with undiluted polychrome methylene blue (Unna) for $2 \frac{1}{2}$ to 3 minutes. After quick differentiation with 90 per cent. alcohol, the specimen is washed, dried, and examined with a $1 / 12$ th oil immersion objective.

Films thus prepared lose a considerable amount of differentiation after 12 hours, and consequently should be examined immediately. One salient factor is demonstrated by this method of examination. In specimens containing: albumin there is a relative increase in the number of alveolar cells, and this, with clinical evidence of consolidation that is usually present, has led us to the conclusion that the albumin is always associated with an alveolitis. The clinical aspect of all the cases has been fully investigated. Analysing these 164 cases they arrange themselves in three groups, indicated in Table II.: Group 1, cases containing tubercle

\section{TABLE II. - Analysis of 164 Cases.}

Group 1

Tubercle bacilli + albumin $+=93$ cases

One case showing no albumin is included in this group; it was, however, only tested for albumin on one occasion.

Therefore, Tubercle bacilli + albumin + cases $=98 \cdot 9$ per cent.

Tubercle bacilli + albumin - cases $=1 \cdot 1$

Group \&.

Tubercle bacilli - albumin $t=39$ cases.

( 5 of clinical tuberculosis.

Albumin in considerable quantity $\left\{\begin{array}{l}1 \text { of doubtful tuberculosis. } \\ 6 \text { cases showing clinical evidence }\end{array}\right.$

(12 cases). $\left\{\begin{array}{l}\text { cases showing clinical evidence } \\ \text { of consolidation, but definitely }\end{array}\right.$ not tuberculous.

(14 clinical tuberculosis.

Albumin a trace (27 cases) ... $\left\{\begin{array}{l}13 \text { cases showing evidence of con- } \\ \text { solidation, definitely non-tuber }\end{array}\right.$ culous.

Group 3.

Tubercle bacilli - albumin - = 32 cases.

25 of bronchitis.

2 , bronchiectasis.

1 ", laryngitis.

4 of clinical tuberculosis (3 very doubtful ; 1 tuberculosis, bu doubtful whether active disease present at time of examination).

bacilli and albumin ; Group 2, cases containing albumin but no tubercle bacilli; and Group 3, cases containing neither tubercle bacilli nor albumin

In Group 1, which comprises 93 specimens, four specimens on first examination failed to give the reaction; but subsequently three of these showed a trace on a second examination, and the fourth case was unfortunately lost sight of. Two of these cases were complicated by tuberculous laryngitis, and the very large amount of frothy sputum present was apparently laryngeal in origin. We suggest that this is a reasonable explanation of the occasional failure of the test in this condition. The two remaining cases were early ones, doing well, with a very small amount of sputum, consisting almost entirely of clear mucin. The very small amount of alveolar exudate present was evidently insufficient to give the albumin rexction. Here we would emphasise the great importance of following our technique with regard to the selection of the purulent portions of the sputum, which alone contain the albumin. The low percentage of cases of pulmonary tuberculosis in which albumin is present obtained by some authors may be due to

14 Besançon and de Jong : Société Médicale des Hôpitaux, Nor. 27th, 1908. 
their neglecting to observe this essential precaution. Roger and Valensi claim that albumin is absent in acute bronchitis, whereas other observers have claimed it to be frequently present. It is admittedly difficult to distinguish clinically between acute bronchitis and the earlier stages of bronchopneumonia, and we suggest that this discrepancy is due to the presence of areas of consolidation in those cases which contained albumin.

In this group 98.9 per cent. of specimens examined contained albumin, an improvement as compared with the first series, when the percentage of such cases was $96 \cdot 4$, due probably to the more sensitive test-viz., that of boiling the filtrate. Traces only of albumin were present in $21 \cdot 5$ per cent. of these cases, and these small quantities are found in specimens almost entirely consisting of mucin and with a very small amount of purulent material. Quantitative estimation of the albumin has been undertaken by Roger and Wourmann ${ }^{15}$ and by Smolizanski. ${ }^{16}$ Their results we consider as unconvincing, and we are unable to find any definite relation between the quantity of albumin present and the amount of lung involvement.

In Group 2 (T.B. - ; albumin +), which include 39 specimens, a large quantity of albumin was present in 12 and a trace in 27. In 20 a clinical diagnosis of active pulmonary tubercle was made, and in only one was it in doubt. The antiformin method for tubercle bacilli was undertaken in all the specimens of this group and the following one. In the 19 non-tuberculous cases the diagnosis was as follows :-

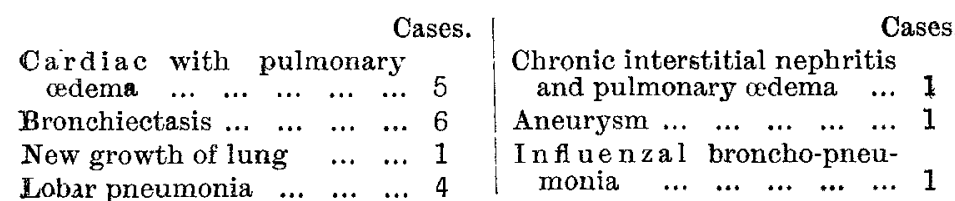

The majority of these conditions do not present great difficulty in diagnosis on clinical grounds alone. The bronchiectatic cases are peculiar inasmuch as only a percentage of these contain albumin, two appearing in the next group of albumin-free specimens.

In Group 3 (no tubercle bacilli and no albumin) 32 cases have been examined and in 25 of these the diagnosis was chronic bronchitis. The remainder include 2 cases of bronchiectasis, 1 of simple laryngitis, and 4 of clinical tuberculosis, all very doubtful, and although they must be recorded as evidence against the conclusion both above and

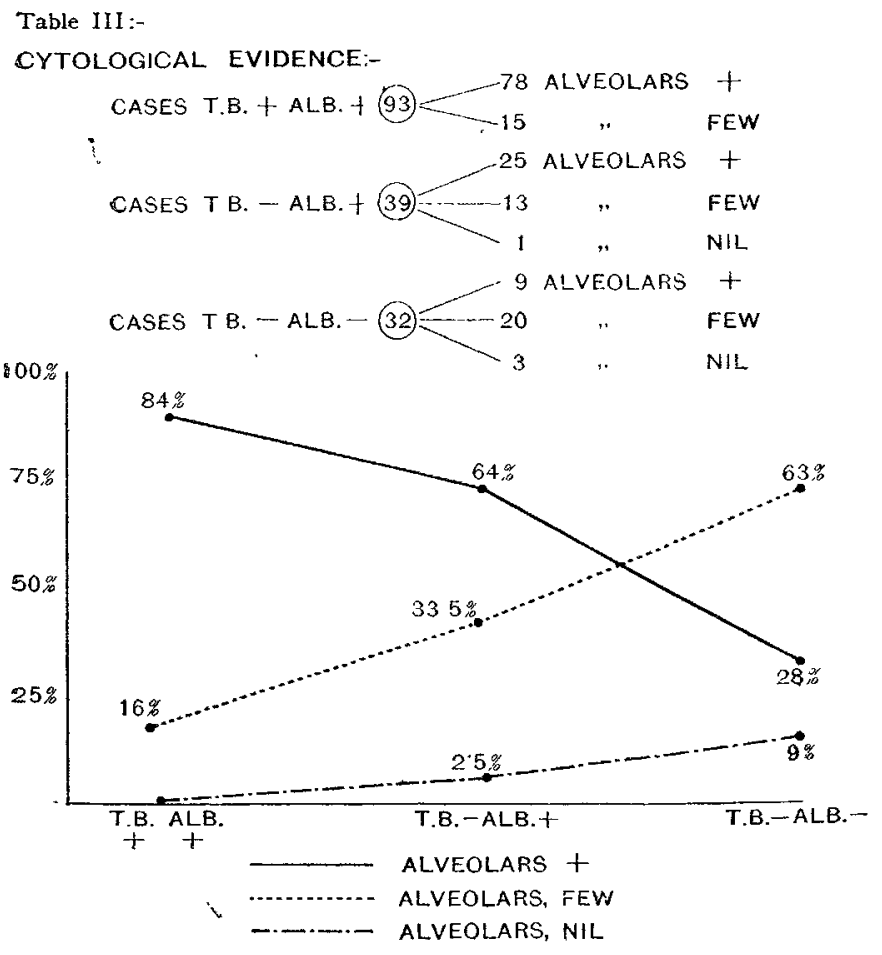

to follow, the doubt as to the diagnosis raised on clinical grounds tends to militate against the importance of the evidence. With reference to the cases of bronchiectasis in Groups 2 and 3, the presence or absence of albumin depends on the amount of alveolitis existing round the cavity. In a

15 Wourmann : Thèse Paris, 1909.

26 Smolizanski : Ibicl., 1911. case of long standing with a considerable degree of fibrosis this is practically negligible, and consequently albumin may be absent. This, however, is the exception, and traces at least were present in 80 per cent. of the cases examined. That albumin is constantly associated with an alveolitis is supported by the clinical signs of consolidation present in cases where the albumin reaction is positive, as well as cytological content of the specirnens.

In the first group 84 per cent. contained alveolar cells in considerable numbers, 16 per cent. a few, and no specimen was free from these mononuclear cells. In the second group the cellular content changes, but not to any marked degree; and in the third group the specimens containing a considerable number of alveolar cells is reduced to 28 per cent. Table III. indicates the behaviour of these cells. Every specimen of sputum will show a few alveolar cells, their presence being usually demonstrable in the small quantity of morning sputum expectorated by the apparently healthy adult. These cells are, however, of quite a different type from the ordinary alveolar, and are of slight, if any, pathological significance. Apart from this there is definite evidence that the number of ordinary alveolar cells is greatly increased in albumin-containing specimens.

Conchusions. - 1. Practically all cases of active pulmonary tuberculosis contain albumin in the sputum. 2. A negative examination for albumin on three successive occasions where tubercle bacilli are also absent, is strong evidence against active tuberculosis. 3. The presence of albumin in doubtful Early cases of pulmonary tuberculosis helps to support this diagnosis. 4. The test is of considerable value in cases of chronic tuberculosis and emphysema as eviajence of active disease.

\section{BASOPHILE PATCHES IN THE PROTO- PLASM OF THE NEUTROPHILE POLYMIORPHS.}

\section{Br A. ROEMMELE, M.B., Ch.B. GlasG., AND}

ROBERT SWEET, M.B., CH.B. GLASG., LATE RESIDEN' HOLSE PHYSICIAYS IN THE GLASGOW ROYAL INFIRMARY.

THE characters of the neutrophile polymorphs we are about to describe were observed in the blood of a Brazilian sailor who was admitted to Dr. McKenzie Anderson's ward, Royal Infirmary, Glasgow, on Nov. 16th, 1910. The history of the case is as follows.

The patient, aged 21 years, was admitted on Nor. 16th. On the 15th he complained of headache and a chill; towards evening he became semicomatose. On admission he could be roused only with difficulty and was semiconscious. The pupils were contracted but reacted to light. The cardiac dulness extended $4 \frac{1}{4}$ inches to the left of the middle line; the right border was at the mid-sternum. On auscultation a systolic murmur was distinct at the mitral area and conducted towards the axilla. Breathing was shallow and rapid but not laboured. Both lungs were resonant all over on percussion; on auscultation the respiratory murmur was harsh, but no râles were present. The temperature was $104^{\circ} \mathrm{F}$., the pulse was 148, and the respirations were 60 . The spleen was not enlarged. Urine was acid, specific gravity 1013. Haze of albumin. The patient recovered consciousness on the 19th, and was dismissed well about three weeks later.

With regard to his previous health, the patient on August 5th, 1910, was in the ward with a typical attack of acute rheumatism, from which he recovered, and was dismissed on Oct. 4th. While in the ward there was a systolic murmur at the apex, but on dismissal both sounds were pure. On examining the blood on admission on Nor. 16th there was a leucocytosis of 90,600 , and we presume that this leucocytosis came on rapidly from the acute onset of the illness. The character of the leucocytes present gave the impression that the polymorphs were in a state of rapid development. Some marrow cells were present and also some dividing marrow cells were noticed in the film. In the neutrophile polymorphs a basophile patchy appearance was observed in the protoplasm of many of the cells, which appeared as though this were a stage in evolution of the development of the mature nucleus in the adult cell. On 